\title{
TENDÊNCIAS TEMPORAIS DA MORTALIDADE E DA LETALIDADE POR \\ LEISHMANIOSE VISCERAL NO BRASIL (2012-2019)
}

\section{Eliete Rodrigues da Silva ${ }^{1}$; Alice Cardoso ${ }^{1}$; Plínio Lima Barreto ${ }^{1}$; Yandra Yssa de Menezes Marinho'; Caíque Jordan Nunes Ribeiro $^{2}$}

\author{
${ }^{1}$ Graduando em Enfermagem, Universidade Federal de Sergipe (UFS), Aracaju, Sergipe. \\ ${ }^{2}$ Doutor em Ciências da Saúde, Universidade Federal de Sergipe (UFS), Aracaju, Sergipe.
}

\section{DOI: 10.47094/IICNNESP.2021/85}

\section{RESUMO}

A leishmaniose visceral (LV) é uma doença tropical negligenciada, potencialmente letal e amplamente distribuída no Brasil. O objetivo é analisar as tendências temporais da letalidade por LV no Brasil de 2012 a 2019. Consiste em um estudo de séries temporais que incluiu os casos notificados de LV no período de 2012 a 2019. A mortalidade e letalidade foram calculadas considerando o desfecho óbito entre pacientes com LV do Sistema de Notificação de Agravos de Notificação As tendências temporais foram examinadas por meio de regressão linear segmentada (Joinpoint). Foram registrados 2.787 óbitos por LV, predominantemente do sexo masculino, adultos, com cor de pele não branca, residentes da zona urbana e provenientes da região Nordeste. Conclui-se que apesar dos esforços nacionais e internacionais para a redução da letalidade por LV, ela ainda é um sério problema de saúde no Brasil.

PALAVRAS-CHAVE: Doenças negligenciadas. Estudos de séries temporais. Epidemiologia.

ÁREA TEMÁTICA: Epidemiologia.

\section{INTRODUÇÃO}

A leishmaniose visceral (LV) é uma antropozoonose, cujo agente etiológico nas Américas é o protozoário Leishmania infantum, transmitido através da picada de fêmeas de flebotomíneos infectadas durante o repasto sanguíneo (BRASIL, 2016). Em 2017, 94\% do total de casos de LV notificados à Organização Mundial da Saúde (OMS) eram provenientes de apenas sete países, dentre eles o Brasil. A LV é uma doença potencialmente letal se não for diagnosticada e tratada precocemente. Portanto, a coinfecção LV-HIV, o diagnóstico tardio e os extremos de idade $(<4$ anos e > 60 anos) são fatores relacionados à maior incidência da doença. O percentual de mortes por LV no Brasil apresentou declínio entre os anos de 2003 e 2007, entretanto, voltou a crescer a partir de 2012 (DONATO et al., 2020). Em consideração a esse cenário, este estudo teve como objetivo analisar as tendências temporais da letalidade por LV no Brasil de 2012 a 2019. 


\section{METODOLOGIA}

Trata-se de um estudo de série temporal que incluiu todos os casos de LV notificados no Sistema de Informação de Agravos de Notificação (SINAN) do Brasil, entre 2012 e 2019. A taxa de letalidade (\%) foi calculada considerando o número de desfechos óbito (causa base ou associada), dividido pelo número de casos e multiplicado por 100. A análise descritiva das características da população do estudo foi representada por meio de tabela. As tendências temporais da letalidade foram analisadas por meio regressão linear segmentada (Joinpoint). Foram calculadas as variações anuais percentuais (APCs) com seus respectivos IC95\%, pois não houve mais de uma inflexão significativa. Os resultados foram analisados da seguinte maneira: APCs significativas e positivas foram consideradas crescentes; APCs significativas e negativas, decrescentes; quando não houve resultado significativo, as tendências foram classificadas estáveis (KIM et al., 2000). Foi considerada uma significância estatística de 5\% $(\mathrm{p}<0,05)$ em todas as análises.

\section{RESULTADOS E DISCUSSÕES}

Foram registrados 28.602 casos de LV no Brasil durante o período do estudo, dos quais 2.787 apresentaram o óbito como desfecho. As mortes por LV ocorreram predominantemente entre casos novos $(91,21 \%)$, do sexo masculino $(68,64 \%)$, provenientes da região Nordeste $(53,35 \%)$, adultos entre 20 e 59 anos (52,39\%), de cor de pele não branca $(79,37 \%)$, com baixa escolaridade $(42,27 \%)$, HIV-negativos $(62,40 \%)$ e residentes na zona urbana $(74,42 \%)$. As maiores letalidades foram observadas na região Sul (18,39\%), entre pacientes do sexo masculino $(10,24 \%), \geq 60$ anos (27,68\%), com baixa escolaridade (11,76\%) e coinfectados por LV-HIV (16,93\%) (Tabela 1). As tendências temporais da letalidade por LV, em nível nacional e regional, foram consideradas estáveis, com exceção da região Norte, a qual apresentou tendência crescente (APC: 7,8; IC95\%: 0,7 a 15,3; $\mathrm{p}<0,05)$.

Os resultados desse estudo corroboram os achados de uma pesquisa que demonstrou incremento das taxas de mortalidade por LV, nas regiões Norte e Sudeste, e da letalidade na região Nordeste, entre 2000 e 2011. Ainda os autores sugerem que a maior letalidade por LV observada na faixa etária adulta e idosa esteja associada à presença de comorbidades prevalentes nessa faixa etária (MARTINS-MELO et al., 2016).

Em relação à coinfecção LV-HIV, sabe-se que o HIV prejudica profundamente os mecanismos imunes necessários para controlar e debelar a infecção por Leishmania. Por outro lado, o impacto no sistema imune causado pela LV contribui para a progressão das doenças associadas ao HIV (LINDOSO et al., 2014). Isto posto, os desfechos de pacientes com coinfecção LV-HIV/ AIDS são piores (TÁVORA; NOGUEIRA; GOMES, 2015). Adicionalmente, estudo realizado em Pernambuco revelou que jovens, adultos do sexo masculino que conviviam com HIV apresentavam maior letalidade por LV (MACHADO et al., 2021). 
Tabela 1. Características da população do estudo.

\begin{tabular}{|c|c|c|c|c|c|c|c|}
\hline \multirow{3}{*}{ Variáveis } & \multicolumn{4}{|l|}{ Óbito } & \multirow{2}{*}{\multicolumn{2}{|c|}{$\begin{array}{l}\text { Total } \\
(n=28.602)\end{array}$}} & \multirow[b]{2}{*}{ Letalidade } \\
\hline & \multicolumn{2}{|c|}{$(n=2.787)$} & \multicolumn{2}{|c|}{$(n=25.815)$} & & & \\
\hline & n & $\%$ & n & $\%$ & n & $\%$ & $\%$ \\
\hline \multicolumn{8}{|l|}{ Região de residência } \\
\hline Norte & 368 & 13,20 & 4.653 & 18,02 & 5.021 & 17,55 & 7,33 \\
\hline Nordeste & 1.487 & 53,35 & 14.505 & 56,19 & 15.992 & 55,91 & 9,30 \\
\hline Sudeste & 636 & 22,82 & 4.726 & 18,31 & 5.362 & 18,75 & 11,86 \\
\hline Sul & 16 & 0,57 & 71 & 0,28 & 87 & 0,30 & 18,39 \\
\hline Centro-oeste & 280 & 10,05 & 1.860 & 7,21 & 2.140 & 7,48 & 13,08 \\
\hline \multicolumn{8}{|l|}{ Tipo de caso } \\
\hline Caso novo & 2.542 & 91,21 & 23.386 & 90,59 & 25.928 & 90,65 & 9,80 \\
\hline Recidiva & 136 & 4,88 & 1.466 & 5,68 & 1.602 & 5,60 & 8,49 \\
\hline Transferência & 45 & 1,61 & 450 & 1,74 & 495 & 1,73 & 9,09 \\
\hline Ignorado & 64 & 2,30 & 513 & 1,99 & 577 & 2,02 & 11,09 \\
\hline \multicolumn{8}{|l|}{ Sexo } \\
\hline Masculino & 1.913 & 68,64 & 16.765 & 65,00 & 18.678 & 65,30 & 10,24 \\
\hline Feminino & 874 & 31,36 & 9.049 & 35,00 & 9.923 & 34,70 & 8,81 \\
\hline Ignorado & - & - & 1 & - & 1 & - & - \\
\hline \multicolumn{8}{|l|}{ Faixa etária } \\
\hline$\leq 4$ anos & 505 & 18,12 & 8.787 & 34,04 & 9.292 & 32,49 & 5,43 \\
\hline 5-19 anos & 143 & 5,13 & 4.886 & 18,93 & 5.029 & 17,58 & 2,84 \\
\hline 20-39 anos & 637 & 22,86 & 5.959 & 23,08 & 6.596 & 23,06 & 9,66 \\
\hline 40-59 anos & 823 & 29,53 & 4.405 & 17,06 & 5.228 & 18,28 & 15,74 \\
\hline$\geq 60$ anos & 678 & 24,33 & 1.771 & 6,86 & 2.449 & 8,56 & 27,68 \\
\hline Ignorado & 1 & 0,04 & 7 & 0,03 & 8 & 0,03 & 12,50 \\
\hline \multicolumn{8}{|l|}{ Cor da pele } \\
\hline Não branca & 2.212 & 79,37 & 21.064 & 81,60 & 23.276 & 81,38 & 9,50 \\
\hline Branca & 377 & 13,53 & 3.178 & 12,31 & 3.555 & 12,43 & 10,60 \\
\hline Ignorado & 198 & 7,10 & 1.573 & 6,09 & 1.771 & 6,19 & 11,18 \\
\hline \multicolumn{8}{|l|}{ Escolaridade } \\
\hline$<12$ anos & 1.178 & 42,27 & 8.842 & 34,25 & 10.020 & 35,03 & 11,76 \\
\hline$\geq 12$ anos & 147 & 5,27 & 1.510 & 5,85 & 1.657 & 5,79 & 8,87 \\
\hline Não se aplica/Ignorado & 1.462 & 52,46 & 15.463 & 59,90 & 16.925 & 59,17 & 8,64 \\
\hline \multicolumn{8}{|l|}{ Zona de residência } \\
\hline Urbana & 2.074 & 74,42 & 18.016 & 69,79 & 20.090 & 70,24 & 10,32 \\
\hline Periurbana & 30 & 1,08 & 252 & 0,98 & 282 & 0,99 & 10,64 \\
\hline Rural & 591 & 21,21 & 6.792 & 26,31 & 7.383 & 25,81 & 8,00 \\
\hline Ignorado & 92 & 3,30 & 755 & 2,92 & 847 & 2,96 & 10,86 \\
\hline \multicolumn{8}{|l|}{ Coinfecção LV-HIV } \\
\hline $\operatorname{Sim}$ & 465 & 16,68 & 2.281 & 8,84 & 2.746 & 9,60 & 16,93 \\
\hline Não & 1.739 & 62,40 & 17.810 & 68,99 & 19.549 & 68,35 & 8,90 \\
\hline Ignorado & 583 & 20,92 & 5.724 & 22,17 & 6.307 & 22,05 & 9,24 \\
\hline
\end{tabular}

Fonte: Elaboração própria 


\section{CONCLUSÃO}

Conclui-se que a LV permanece um sério problema de saúde pública no Brasil. As mortes por LV foram mais frequentes entre pacientes do sexo masculino, adultos, de cor de pele não branca, com baixa escolaridade, HIV-negativos, residentes da zona urbana e provenientes da região Nordeste. Embora a letalidade tenha se mantido estável em nível nacional e na maioria das regiões, a região Norte apresentou tendência crescente.

\section{PRINCIPAIS REFERÊNCIAS}

DONATO, L. E.; DE FREITAS, L. R. S.; DUARTE, E. C.; ROMERO, G. A. S. Visceral leishmaniasis lethality in Brazil: An exploratory analysis of associated demographic and socioeconomic factors. Revista da Sociedade Brasileira de Medicina Tropical, v. 53, e20200007, p. 1-8, 2020.

MACHADO, C. A. L.; SEVÁ, A. DA P.; SILVA, A. A. F. A.; HORTA, M. C. Epidemiological profile and lethality of visceral leishmaniasis/human immunodeficiency virus co-infection in an endemic area in Northeast Brazil. Revista da Sociedade Brasileira de Medicina Tropical, v. 54, e0795-2020, p. $1-8,2021$.

MARTINS-MELO, F. R.; RAMOS, A. N.; ALENCAR, C. H.; HEUKELBACH, J. Trendsand spatial patterns of mortality related to neglected tropical diseases in Brazil. Parasite Epidemiology and Control, v. 1, n. 2, p. 56-65, 2016.

RIBEIRO, C. J. N. et al. Space-time risk cluster of visceral leishmaniasis in brazilian endemic region with high social vulnerability: An ecological time series study. PLoS Neglected Tropical Diseases, v. 15, n. 1, p. 1-20, 2021. 